\title{
Marriage Patterns and Reproductive Decision-Making in the Inhabitants of a Single Muslim Village during a 50-Year Period
}

\author{
Joël Zlotogora ${ }^{\text {a, b }}$ Stavit A. Shalev ${ }^{\text {c, d }}$ \\ ${ }^{a}$ Department of Community Genetics, Public Health Services, Ministry of Health, Jerusalem, ${ }^{b}$ The Hebrew University \\ of Jerusalem, Jerusalem, ' Genetic Institute, Emek Medical Center, Afula, and ${ }^{\mathrm{d}}$ Rappaport School of Medicine, \\ Technion, Haifa, Israel
}

\section{Key Words}

Arab $\cdot$ Muslim $\cdot$ Consanguinity $\cdot$ Israel

\begin{abstract}
Objectives: In a single Muslim village in Israel, established about 300 years ago by a small number of founders, a longitudinal study was conducted on the types of marriages and their effects on family planning, with the age at which a woman had her first child and the size of the family assessed. Methods: The information for the analysis was extracted from a detailed database including individuals residing in and originating from the village. Results: A shift from the practice of marrying a close relative, in particular patrilateral parallel first-cousin marriages, to marrying a more remotely related individual was observed during the study period. Another major change was a significant reduction in the mean number of children born per woman from 8.7 among women born between 1930 and 1939 to 4.7 among those born between 1960 and 1969. In families in which the parents were biological relatives, the number of children was always higher than in families in which the parents were unrelated. The mean age of the mother at the birth of her first child progressively increased during the study period from 20.9 to 23.7 years. The maternal age was always higher when the
\end{abstract}

spouses were from different villages than when they were biological relatives, either being first cousins or more distantly related. Conclusions: Significant sociodemographic changes were observed during the course of the last 50 years. However, the consequences of the long-lasting isolation of the population remain and still exert an important effect on present-day medical problems in the village.

(c) 2014 S. Karger AG, Basel

\section{Introduction}

Consanguineous marriages are common in many populations worldwide and of significant interest to the medical community. However, many studies examining the effects of consanguinity lacked adequate controls for nongenetic variables, making it difficult to draw firm conclusions on the relevance of the results obtained [1]. We therefore decided to focus on a well-defined population, i.e. a single Muslim village in Israel, established about 300 years ago by a small number of founders. A large Arab town as well as several other Arab villages are located within a $10-\mathrm{km}$ diameter of the village, which was chosen at random in 1995 as the site for a pilot project implementing genetic counseling in the Arab communi-

\section{KARGER}

E-Mail karger@karger.com

www.karger.com/hhe (c) 2014 S. Karger AG, Base

0001-5652/14/0774-0010\$39.50/0
Joël Zlotogora

Department of Community Genetics

Building 67, Sheba Medical Center

IL-52621 Ramat Gan (Israel)

E-Mail zlotogora@gmail.com 
Table 1. Type of marriages in the village according to the year of birth of the woman

\begin{tabular}{|c|c|c|c|c|c|c|c|c|c|c|c|c|c|c|c|c|}
\hline & \multicolumn{2}{|c|}{$\begin{array}{l}1930-1939 \\
(\mathrm{n}=139)\end{array}$} & \multicolumn{2}{|c|}{$\begin{array}{l}1940-1949 \\
(\mathrm{n}=198)\end{array}$} & \multicolumn{2}{|c|}{$\begin{array}{l}1950-1959 \\
(\mathrm{n}=357)\end{array}$} & \multicolumn{2}{|c|}{$\begin{array}{l}1960-1969 \\
(\mathrm{n}=598)\end{array}$} & \multicolumn{2}{|c|}{$\begin{array}{l}1970-1979 \\
(\mathrm{n}=687)\end{array}$} & \multicolumn{2}{|c|}{$\begin{array}{l}1980-1989 \\
(\mathrm{n}=486)\end{array}$} & \multicolumn{2}{|c|}{$\begin{array}{l}1990 \\
\text { and later } \\
(\mathrm{n}=69)\end{array}$} & \multicolumn{2}{|c|}{$\begin{array}{l}\text { All } \\
(\mathrm{n}=2,534)\end{array}$} \\
\hline \multicolumn{17}{|l|}{ Related as second cousin or closer } \\
\hline Related as first cousin or closer & 32 & 23 & 53 & 26.7 & 77 & 21.5 & 125 & 20.9 & 121 & 17.6 & 53 & 10.9 & 6 & 8.7 & 467 & 18.4 \\
\hline Double first cousin & 1 & 0.7 & 5 & 2.5 & 3 & 0.8 & 1 & 0.2 & 0 & 0 & 1 & 0.4 & 0 & 0 & 11 & 0.4 \\
\hline First cousin cross-patrilineal & 4 & 2.9 & 5 & 2.5 & 12 & 3.4 & 19 & 3.2 & 18 & 2.6 & 12 & 2.5 & & & 70 & 2.8 \\
\hline First cousin cross-matrilineal & 6 & 4.3 & 11 & 5.6 & 12 & 3.4 & 33 & 5.5 & 34 & 4.9 & 15 & 3.1 & 1 & 1.5 & 112 & 4.0 \\
\hline $\begin{array}{l}\text { Not first cousin but second cousin } \\
\text { and closer }\end{array}$ & 41 & 29.5 & 39 & 19.7 & 62 & 17.3 & 94 & 15.6 & 85 & 12.4 & 56 & 11.5 & 6 & 8.7 & 383 & 15.1 \\
\hline Total & 73 & 52.5 & 92 & 46.5 & 139 & 38.9 & 219 & 36.6 & 206 & 30.0 & 109 & 22.4 & 12 & 17.4 & 850 & 33.5 \\
\hline
\end{tabular}

ty. The present study aimed to follow the marriage patterns in the village and their effects on family planning in terms of the age at which a woman had her first child and the completed size of the family.

\section{Subjects and Methods}

In this study, we included couples who were living in the village and where the husband was born in the village. In this patriarchal community, a woman almost always lives with or close to her husband's family; therefore, if she marries outside her village of birth, she will move to and live in her husband's village. The woman's year of birth was used as a reference since it is the date most frequently recorded in the database.

It was almost always possible to determine the exact relationship between the spouses when both partners were descendants of the founders of the village. For a small number of couples where the origin of one of the spouses was unknown and where the husband was born in the village but his relationship to the founders was unknown, the couple was classified as distantly related. For those couples where the origin of the woman was unknown, the spouses were classified as having been born in different villages.

The database was initiated by gathering information through personal interviews with adult couples living in the village. All data on the inhabitants of the village were collected systematically using a pedigree computer program (Reunion, Leister Productions, Inc., Mechanicsburg, Pa., USA) [2, 3] and, since 1995, have been updated yearly. The information collected included details of all live births and malformations/genetic diseases diagnosed either at birth or as a result of a genetic consultation, with data obtained from the Israeli registry of malformations in live newborn infants and the genetic clinic at the Emek Hospital [3].

The study was performed according to a protocol approved by the Institutional Review Board of the Emek Medical Center.

Marriage Patterns and Family Planning in a Muslim Village in Israel

\section{Results}

\section{Type of Marriages according to the Degree of} Relationship

Data on the types of marriages in the village have been published previously and are updated in table $1[2$, 3 ]. Over the years, the proportion of double first-cousin $(\mathrm{F}=0.125)$ and first-cousin marriages $(\mathrm{F}=0.0625)$ declined from $23 \%$ to less than $10 \%$ (table 1 ). This decline was almost entirely due to a reduction in the number of patrilateral parallel first-cousin marriages, i.e. marriages between the children of brothers. Patrilateral parallel first-cousin marriages accounted for $13.7 \%$ of all marital unions among women who married in the second half of the 20th century, i.e. who were born between 1930 and 1939, but for less than $3 \%$ of the marriages among women who married at the beginning of the 21 st century, i.e. who were born after 1989. In addition to the reduction in the proportion of first-cousin marriages, there was a decrease in marriages between second cousins and closer (but less than first cousins) from 29.5\% among women born between 1930 and 1939 to less than $10 \%$ among women born after 1989. Therefore, in total, during the study period, there was a significant reduction in all types of marriages between spouses who were second cousins and closer ( $\mathrm{F} \geq 0.0156)$ from $52.5 \%$ to less than $20 \%$.

In parallel with the reduction in the proportion of marriages between close relatives, an increase in the proportion of marriages between distant relatives was observed (from 33.1 to $59.4 \%$ ). By comparison, the propor- 
tion of marriages between partners born outside the village remained stable, representing between 20 and $30 \%$ of total marriages during the study period.

\section{Number of Children per Family}

The mean number of children born to a woman declined from 8.7 among women born between 1930 and 1939 to 4.7 among those born between 1960 and 1969 (table 2). In families in which the parents were biological relatives, the number of children was always higher than in families in which the parents were unrelated. However, in parallel with the reduction in the total number of children, during the study period the difference in the completed family size between the two groups decreased from 3.0 children among women born between 1930 and 1939 to 0.8 children among women born between 1960 and 1969.

For women born between 1920 and 1949 and married to a biological relative, the mean number of children was lower when the spouses were first cousins than when they were more distantly related. However, this difference also disappeared with time in parallel with the significant general reduction in the mean number of children per family.

\section{Maternal Age at First Birth}

The mean age of the mother at the birth of her first child progressively increased during the period of the study (table 3) and was always higher when the spouses originated from different villages than when they were related, either being first cousins or distantly related. In addition, when the spouses were from different villages, there were significantly more marriages in which the wife was older than her husband (24\% of marriages), and among these couples the mean age of the woman at the first birth was significantly higher (data not shown).

\section{Discussion}

In 2011, the population of Israel included 7,836,600 inhabitants, of whom about $80 \%$ were Jews and $15 \%$ Muslim Arabs [4]. Approximately half of the Muslim population lives in small, relatively isolated localities, which were settled by small numbers of founders. The present study was performed in a randomly chosen Muslim locality with demographic features characteristic of the Muslim population in general; therefore, the observations reported reflect and are relevant to most of the Muslim population of Israel. Since the establishment of the state of Israel in 1948, the Arab population has un-
Table 2. Mean number of children per family

\begin{tabular}{llllll}
\hline & $\begin{array}{l}\text { Not } \\
\text { related }\end{array}$ & $\begin{array}{l}\text { First } \\
\text { cousins }\end{array}$ & $\begin{array}{l}\text { Related, } \\
\text { less than } \\
\text { first cousins }\end{array}$ & $\begin{array}{l}\text { All } \\
\text { related }\end{array}$ & Total \\
\hline $1930-1939$ & 6 & 7.7 & 9.5 & 9 & 8.7 \\
$1940-1949$ & 6.5 & 6.9 & 8.2 & 7.8 & 7.7 \\
$1950-1959$ & 4.3 & 5.9 & 5.6 & 5.7 & 5.5 \\
$1960-1969$ & 4.1 & 5.1 & 4.8 & 4.9 & 4.7 \\
\hline
\end{tabular}

Table 3. Mean age of the mother at the birth of her first child

\begin{tabular}{lllll}
\hline & $\begin{array}{l}\text { Not } \\
\text { related }\end{array}$ & $\begin{array}{l}\text { First } \\
\text { cousins }\end{array}$ & $\begin{array}{l}\text { Related, } \\
\text { less than } \\
\text { first cousins }\end{array}$ & Total \\
\hline $1930-1939$ & - & 21.3 & 20.4 & 20.9 \\
$1940-1949$ & 24.8 & 21.6 & 21.6 & 21.8 \\
$1950-1959$ & 25.2 & 22.5 & 22.8 & 22.9 \\
$1960-1969$ & 25.8 & 22.8 & 23.4 & 23.7 \\
\hline
\end{tabular}

dergone many sociodemographic changes, in particular a huge increase in numbers, almost all as a result of internal growth.

In the study village, an 8-fold increase in the size of the population was registered - from 1,500 individuals in 1955, the first year for which statistical data were available, to 11,700 in 2011 [4]. An important cause for the rapid expansion of the Arab population was the very significant health improvement achieved since the creation of the country. For instance, infant mortality rates among Muslim Arabs decreased from more than 60 per 1,000 live births in the early 1950s to 6.7 per 1,000 live births in 2011 [4]. In the study village, the mean number of children per family during the second part of the 20th century was more than 7, and with the improvement in health conditions most of the children survived and gave birth to children who in turn reproduced in the next generation.

During the whole period of the study, approximately $75 \%$ of marriages remained between spouses who were descendants of the village founders, and therefore the spouses were related to some degree. However, over the years, a significant change in the pattern of marriages was observed, from a majority contracted between close relatives $(\mathrm{F} \geq 0.0625)$ to a majority contracted between distant relatives. In the second half of the 20th century, most of the marriages were among second cousins and more closely related individuals $(\mathrm{F} \geq 0.0156)$. More than half of these
Zlotogora/Shalev 
marriages were between first cousins, the majority being patrilateral parallel first-cousin marriages, a type of marriage traditionally preferred among Muslim Arabs. Fifty years later, at the beginning of the 21st century, the situation had changed significantly and all types of marriages between close relatives had become progressively less common.

In recent decades, a strong but often exaggerated emphasis has been placed on the adverse medical consequences of consanguineous marriages. Following the success of public health campaigns to reduce infant mortality, mainly by combatting infectious diseases, congenital diseases/malformations have remained an important cause of infant mortality in many developing countries, associated in part with the expression of recessive disease genes in the progeny of consanguineous couples. Many researchers therefore thought that public health campaigns against consanguineous marriages should be developed, with some even proposing their prohibition on medical grounds [1]. This attitude featured prominently in Israel [5], and it is possible that, as a result, marriages between close biological relatives and in particular patrilineal parallel unions began to be avoided.

There are various reasons underlying the preference for consanguineous marriages, one being the continuation of pre-existing shared social relationships after marriage. In a close community such as the one described here, the conservation of family ties, assets and values can also be achieved by marriage with a remote biological relative. In addition, it is possible that the preference for marriages within the expanded family has persisted because until the end of high school, younger family members live in a quite closed society, but with the opportunity to form personal ties with neighboring children who are biological relatives.

One of the aims of the present study was to assess the effect of consanguinity on family planning in terms of the age at which a woman had her first child and the completed size of the family. During the period of the study, a progressive rise was observed in the maternal age at which the first child was born, namely from 20.9 to 23.7 years. This trend was similar to that in the whole Israeli Muslim population, where the mean maternal age at the birth of the first child increased progressively to 23.4 in 2011. An analysis conducted across each of the time periods on the relationships between spouses showed that the age of the women at their first birth was higher in couples in which the spouses were either distantly related or unrelated.

Comparing the number of children per family in different groups of women who had completed their reproductive life, a significant reduction was observed in the mean number of children according to their year of birth: from 8.7 in families in which the mother was born between 1930 and 1939 to 4.7 per family for mothers born between the years 1960 and 1969. This finding also accords with the overall situation in the general Muslim population in Israel, where the number of children per family decreased from 9.23 for children born between 1965 and 1969 to 3.51 for those born in 2011 [4].

In each of the age groups in the study village, the number of children per family was higher when the parents were biological relatives than when the parents were unrelated. The comparison in the mean number of live births of first-cousin versus unrelated couples has been made in several studies and was further analyzed in a meta-analysis of 41 studies conducted in 9 countries, including Israel [1]. Across the study populations, first-cousin couples had, on average, more children when compared with co-resident unrelated couples. However, there were wide variations between the surveys, mainly reflecting temporal and geographical differences as well as differences in the study design. The present study included only women who had completed their reproductive lives and who were living in a single village and under very similar lifestyle conditions during a 50-year period. Among this group of women, in each of the time intervals, the number of children born to families with spouses who were first cousins was consistently higher than in families in which the spouses were unrelated.

Looking at the changes in the prevalence of consanguinity, in family size and in the age at which a woman had her first child, one might assume that the same factors (e.g. educational background) had influenced the findings. However, in the first two decades when the average family size was large and comprised more than 7 children, the number of children born was significantly higher among distantly related spouses than among spouses who were first cousins. These differences disappeared later as the families progressively became smaller. It therefore seems that other factors influencing the size of the family may have included a comparative reduction in the family size of more closely related spouses due to fertility problems and/or higher pregnancy losses. In order to determine whether these observations are significant, other similar studies would need to be performed.

Since the establishment of the state of Israel, significant social changes have been observed in the study village, as in most of the national Muslim population. Among these changes, a shift from marrying a close biological relative to marrying a more remotely related spouse became evident. Another change was a significant reduction in the 
Table 4. Autosomal recessive diseases diagnosed in the village

\begin{tabular}{|c|c|c|c|c|}
\hline & Disorder & Families, $\mathrm{n}$ & Gene & Mutation(s) \\
\hline \multicolumn{5}{|c|}{ Diseases in which the molecular basis has been characterized } \\
\hline 1 & Deafness & 43 & GJB2 & 35Gdel, W77R, V37I \\
\hline 2 & Retinitis pigmentosa & 27 & PCRD & $\mathrm{R} 22 \mathrm{X}$ \\
\hline 3 & Sickle cell thalassemia & 5 & HBB & N37, IVS2, IVS1 \\
\hline 4 & Sickle cell anemia & 4 & $\mathrm{HBB}$ & G6V \\
\hline 5 & Glutaric acidemia type II & 4 & ETFDH & $1084 \mathrm{G}>\mathrm{A}$ \\
\hline 7 & Familial Mediterranean fever & 2 & MEFV & V726A, M680I, M694I \\
\hline 8 & Gaucher's disease & 3 & GBA & N370S \\
\hline 9 & Metachromatic leukodystrophy & 1 & ARSA & Q190H \\
\hline 10 & Opsismodysplasia & 1 & GPC6 & Deletion \\
\hline \multicolumn{5}{|c|}{ Diseases in which the molecular basis has not been characterized } \\
\hline 11 & Arthrogryposis & 3 & & \\
\hline 15 & Hyperphenylalaninemia & 1 & & \\
\hline 16 & Pyruvate carboxylase deficiency & 1 & & \\
\hline 17 & Aplastic anemia & 1 & & \\
\hline 18 & Hemochromatosis & 1 & & \\
\hline 19 & Laron syndrome & 1 & & \\
\hline 20 & Familial intrahepatic cholestasis & 1 & & \\
\hline $21-27$ & Probably autosomal recessive disorders & 1 family e & & \\
\hline
\end{tabular}

size of the family and the progressively older age of the woman at the birth of her first child [4]. However, in spite of these changes and as previously reported, the long-lasting isolation of the population has remained an important issue which continues to exert a significant influence on the pattern of medical problems in the village. For instance, the rates of malformations and major medical conditions during pregnancy and the first 5 years of life observed in the village were comparatively high (5.5\% of the live births) [3]. This rate of malformations is an average calculated throughout a 10-year period (1992-2003) and ranges from the rate of $3.6 \%$ observed when the spouses were unrelated to the significantly higher rates observed when the spouses were either first cousins $(7.8 \%)$ or more distantly related (5.3\%) [3].

Another significant observation in the village was that, in spite of the progressive changes in personal decisionmaking in terms of spouse selection and family planning demonstrated in the present article, the patterns of socialpersonal behavior over many preceding generations have influenced the net outcome seen as higher rates of autosomal recessive disorders. In the village, the prevalence of connexin 26-related deafness and retinitis pigmentosa is very high, and a large number of other distinct rare auto- somal recessive disorders have been observed (table 4) [6]. Among the autosomal recessive diseases in which the molecular basis was identified, some mutations, e.g. those responsible for thalassemia, sickle cell disease, familial Mediterranean fever and deafness [GJB2, Gdel35], are also frequently seen in the surrounding populations, while others such as [GJB2, W77R], [PCRD, R22X] or [ARSA, Q190H] are specific to the population and probably arose de novo and up to now have not been found in neighboring villages. The distribution of the mutations among the inhabitants of the village showed that mutations which currently are very frequent either were present in the founders or were introduced soon after the establishment of the village, while mutations that are rare nowadays were recently introduced [7].

The observations made in the village as well as in other villages and Bedouin tribes in Israel are the basis for targeted genetic counseling and screening aimed at communities with elevated rates of consanguineous marriages [8]. The overall aim is to offer ways to reduce the medical risks associated with consanguinity on the basis of the knowledge accumulated in the population, while leaving the final choice of marriage partners to the individuals themselves. 


\section{References}

1 Bittles A: Consanguinity in Context. Cambridge, Cambridge University Press, 2012.

$>2$ Zlotogora J, Habiballa H, Odatalla A, Barges S: Changing family structure in a modernizing society: a study of marriage patterns in a single Muslim village in Israel. Am J Human Biol 2002;14:680-682.

3 Zlotogora J, Shalev SA: The consequences of consanguinity on the rates of malformations and major medical conditions at birth and in early childhood in inbred populations. Am J Med Genet 2010;152A:2023-2028.

4 Statistical Abstract of Israel. Jerusalem, Israel. Central Bureau of Statistics, 2012.

5 Strulov A: The Western Galilee experience: reducing infant mortality in the Arab population. Isr Med Assoc J 2005;7:483-486.

6 Zlotogora J, Shalev S, Habiballa H, Barges S: Genetic disorders among Palestinian Arabs. 3. Autosomal recessive disorders in a single village. Am J Med Genet 2000;92: 343-345.

7 Zlotogora J, Hujerat Y, Barges S, Shalev SA, Chakravarti A: The fate of 12 recessive mutations in a single village. Ann Hum Genet 2007; 71:202-208.

$>8$ Zlotogora J, Carmi R, Lev B, Shalev SA: A targeted population carrier screening program for severe and frequent genetic diseases in Israel. Eur J Hum Genet 2009; 17:591-597. 